OPEN ACCESS

Edited by:

Teizo Yoshimura,

Okayama University, Japan

Reviewed by:

Marlene Wolf,

University of Bern, Switzerland

Jean-Yves Springael,

Université Libre de Bruxelles, Belgium

*Correspondence:

Paul Proost

paul.proost@kuleuven.be

Specialty section:

This article was submitted

to Cytokines and Soluble

Mediators in Immunity,

a section of the journal

Frontiers in Immunology

Received: 15 March 2017

Accepted: 20 April 2017

Published: 10 May 2017

Citation:

Vanheule $V$, Boff $D$, Mortier A, Janssens $R$, Petri B, Kolaczkowska E, Kubes P, Berghmans N, Struyf S,

Kungl AJ, Teixeira MM, Amaral FA and Proost $P$ (2017) CXCL9-Derived

Peptides Differentially Inhibit

Neutrophil Migration In Vivo

through Interference with

Glycosaminoglycan Interactions.

Front. Immunol. 8:530.

doi: 10.3389/fimmu.2017.00530

\section{CXCL9-Derived Peptides Differentially Inhibit Neutrophil Migration In Vivo through Interference with Glycosaminoglycan Interactions}

\author{
Vincent Vanheule', Daiane Boff ${ }^{1,2}$, Anneleen Mortier ${ }^{1}$, Rik Janssens ${ }^{1}$, Björn Petri, \\ Elzbieta Kolaczkowska ${ }^{4,5}$, Paul Kubes ${ }^{6}$, Nele Berghmans', Sofie Struyf', \\ Andreas J. Kungl ${ }^{7}$, Mauro Martins Teixeira ${ }^{2}$, Flavio Almeida Amaral ${ }^{2}$ and Paul Proost ${ }^{1 *}$ \\ ${ }^{1}$ Laboratory of Molecular Immunology, Department of Microbiology and Immunology, Rega Institute for Medical Research, \\ KU Leuven, Leuven, Belgium, '2 Departamento de Fisiologia e Biofisica, Instituto de Ciencias Biologicas, Universidade Federal \\ de Minas Gerais, Belo Horizonte, Minas Gerais, Brazil, ${ }^{3}$ Mouse Phenomics Resource Laboratory, Department of \\ Microbiology, Immunology and Infectious Diseases, Cumming School of Medicine, Snyder Institute for Chronic Diseases, \\ University of Calgary, Calgary, AB, Canada, ${ }^{4}$ Department of Evolutionary Immunology, Institute of Zoology, Jagiellonian \\ University, Krakow, Poland, ${ }^{5}$ Laboratory of Immunobiology, Department of Microbiology and Immunology, Rega Institute for \\ Medical Research, KU Leuven, Leuven, Belgium, ${ }^{6}$ Immunology Research Group, Department of Physiology and \\ Pharmacology, Snyder Institute for Chronic Diseases, University of Calgary, Calgary, AB, Canada, ${ }^{7}$ Department of \\ Pharmaceutical Chemistry, Institute of Pharmaceutical Sciences, Karl-Franzens Universität, Graz, Austria
}

Several acute and chronic inflammatory diseases are driven by accumulation of activated leukocytes due to enhanced chemokine expression. In addition to specific $G$ protein-coupled receptor-dependent signaling, chemokine-glycosaminoglycan (GAG) interactions are important for chemokine activity in vivo. Therefore, the GAG-chemokine interaction has been explored as target for inhibition of chemokine activity. It was demonstrated that CXCL9(74-103) binds with high affinity to GAGs, competed with active chemokines for GAG binding and thereby inhibited CXCL8- and monosodium urate (MSU) crystal-induced neutrophil migration to joints. To evaluate the affinity and specificity of the $\mathrm{COOH}$-terminal part of CXCL9 toward different GAGs in detail, we chemically synthesized several $\mathrm{COOH}$-terminal CXCL9 peptides including the shorter CXCL9(74-93). Compared to CXCL9(74-103), CXCL9(74-93) showed equally high affinity for heparin and heparan sulfate (HS), but lower affinity for binding to chondroitin sulfate (CS) and cellular GAGs. Correspondingly, both peptides competed with equal efficiency for CXCL8 binding to heparin and HS but not to cellular GAGs. In addition, differences in anti-inflammatory activity between both peptides were detected in vivo. CXCL8induced neutrophil migration to the peritoneal cavity and to the knee joint were inhibited with similar potency by intravenous or intraperitoneal injection of CXCL9(74-103) or CXCL9(74-93), but not by CXCL9(86-103). In contrast, neutrophil extravasation in the MSU crystal-induced gout model, in which multiple chemoattractants are induced, was not affected by CXCL9(74-93). This could be explained by (1) the lower affinity of CXCL9(74-93) for CS, the most abundant GAG in joints, and (2) by reduced competition with GAG binding of CXCL1, the most abundant ELR+ $\mathrm{CXC}$ chemokine in this gout 
model. Mechanistically we showed by intravital microscopy that fluorescent CXCL9 (74-103) coats the vessel wall in vivo and that CXCL9(74-103) inhibits CXCL8-induced adhesion of neutrophils to the vessel wall in the murine cremaster muscle model. Thus, both affinity and specificity of chemokines and the peptides for different GAGs and the presence of specific GAGs in different tissues will determine whether competition can occur. In summary, both CXCL9 peptides inhibited neutrophil migration in vivo through interference with GAG interactions in several animal models. Shortening CXCL9(74-103) from the $\mathrm{COOH}$-terminus limited its GAG-binding spectrum.

Keywords: chemokine, CXCL9, glycosaminoglycan, neutrophil, anti-inflammatory, gout, cremaster muscle

\section{INTRODUCTION}

Several acute and chronic inflammatory diseases, such as gout and rheumatoid arthritis, are characterized by enhanced expression of chemokines and accumulation of activated leukocytes in tissues (1-6). Chemokines or chemotactic cytokines are proteins, consisting of 60-110 amino acids, which play an important role in the migration of leukocytes (7-10). Chemokines are classified into $\mathrm{C}, \mathrm{CC}, \mathrm{CXC}$, and $\mathrm{CX}_{3} \mathrm{C}$ subfamilies, based on the arrangement of conserved $\mathrm{NH}_{2}$-terminal cysteine motifs. For most chemokines an alternative biological classification can be made between homeostatic or constitutively expressed chemokines, and inflammatory or inducible chemokines. The latter subclass is locally secreted by tissue cells and resident leukocytes upon infection or tissue damage, thereby creating a gradient along which leukocytes can migrate from the blood vessel to the site of inflammation (11-14). To create such a leukocyte migration inducing gradient, it is necessary that chemokines are presented on the endothelium at the site of inflammation through binding to glycosaminoglycans (GAGs), thereby preventing chemokine diffusion and degradation and retaining high local chemokine concentrations. Subsequently, GAG-bound chemokines interact with their G protein-coupled receptors (GPCRs), expressed by specific circulating leukocyte subtypes. This results in adhesion to and extravasation of leukocytes through the endothelium (15-17). Once leukocytes enter the tissue, they can migrate to the site of inflammation through the gradient of local GAG-bound chemokines. The binding of chemokines to GAGs has been proven to be indispensable for chemokine activity in vivo (18-20). Chemokine variants with mutations in their GAG-binding motif showed inactive in vivo due to abrogated GAG binding, although receptor binding and chemotactic activity in vitro are seldom affected $(21,22)$. In addition, leukocytes of mice with disturbed heparan sulfate (HS) synthesis in endothelial cells and leukocytes showed reduced chemokine-induced migration (23).

Because of their essential role for the migration of leukocytes, chemokines and their GPCRs can serve as potential targets for the development of new anti-inflammatory drugs (24-26). Several neutralizing ligands or antibodies, modified chemokines or small molecules have been developed as antagonists (27-30). However, only two chemokine receptor antagonists are currently used as therapeutics, namely, Maraviroc (a CCR5 antagonist) and AMD3100 (a CXCR4 antagonist) $(31,32)$. Remarkably, these antagonists are not used as anti-inflammatory drugs, but, respectively, as an inhibitor of human immunodeficiency virus infection and as a stem cell mobilizer. Recently, intact modified chemokines were developed that interfere with the binding of chemokines to GAGs $(33,34)$. These modified chemokines have, in comparison with their natural human chemokine counterpart, an enhanced affinity for GAGs but a decreased affinity for their GPCRs. In this way, the modified chemokines or decoy chemokines can compete with functional chemokines for GAG binding. Thereby, they reduce chemokine immobilization and presentation and enhance the inhibition of chemokine-induced leukocyte migration. It has been shown that PA401, aCXCL8-based decoy protein, exerts strong antiinflammatory activity in vivo (35-38). Also CCL2- and CXCL12based decoy proteins with high GAG-binding affinity and reduced activity on GPCRs have been developed $(39,40)$. Interference with GAG interactions also forms the basis for the inhibition of lymphocyte migration with the spiegelmer NOX-A12 (41). This RNA oligonucleotide competes with GAGs for the binding to CXCL12, leading to neutralization of CXCL12 activity in vivo. More recently, $\mathrm{COOH}$-terminal peptides of the chemokine CXCL9 or monokine induced by interferon- $\gamma$ (MIG) were described as potent GAGbinding peptides $(42,43)$. The CXCL9(74-103) peptide could inhibit the in vivo chemotactic activity of CXCL8 by competing with CXCL8 for the binding to GAGs. Also in a murine model of monosodium urate (MSU) crystal-induced gout, the peptide was able to inhibit neutrophil extravasation. Reducing the length of the CXCL9 peptide gradually decreased the capacity to compete with CXCL8 for GAG binding and CXCL9(86-103) was unable to inhibit chemotactic activity of CXCL8 in vivo. These data stress the importance of amino acids 74-78 and two typical heparin-binding motifs (BBXB and BBBXXB), present in CXCL9(74-103), for the GAG-binding characteristics.

In this study, we investigated in more detail the specificity of chemokine-derived GAG-binding peptides and we evaluated the potential of such peptides to interfere with in vivo neutrophil adhesion and migration to different tissues (peritoneal cavity, joints, and muscles) in mice.

\section{MATERIALS AND METHODS}

\section{Cells}

Chinese hamster ovary $(\mathrm{CHO})$ cells were a gift from $\mathrm{M}$. Parmentier (ULB, Brussels, Belgium) and were cultured in Ham's F-12 medium (with L-glutamine; Lonza, Belgium) supplemented 
with $10 \%$ fetal calf serum (FCS) and $0.8 \%$ G418 (Geneticin ${ }^{\circledR}$; Life Technologies), as described (44). To inhibit sulfation of cellular GAGs, CHO cells were cultured in the presence of $100 \mathrm{mM}$ sodium chlorate $\left(\mathrm{NaClO}_{3}\right)$ for $24 \mathrm{~h}$ as previously described (42).

\section{Mice}

Animal experiments at the Rega Institute for Medical Research, University of Leuven, were carried out in female adult NMRI mice, purchased from Elevage Janvier (Le Genest Saint Isle, France), in agreement with the Ethical Committee for Animal Care and Use of the KU Leuven and in adherence to the international guidelines for animal ethics and welfare. Mouse studies at the Federal University of Minas Gerais were performed in adult C57BL/6J mice. The experiments were approved by the Animal Ethical Committee of the Federal University of Minas Gerais. Mice were sacrificed by i.p. injection of an overdose of nembutal or ketamine $(150 \mathrm{mg} / \mathrm{kg})$ and xylazine $(20 \mathrm{mg} / \mathrm{kg})$ prior to the collection of joint lavages. For the intravital microscopy studies, male C57Bl/6J mice were purchased from Jackson Laboratories (Bar Harbor, ME, USA). Animals were maintained in a specific pathogen-free environment at the University of Calgary Animal Resource Centre. All experimental animal protocols were approved by the University of Calgary Animal Care Committee and were in compliance with the Canadian Council for Animal Care Guidelines.

\section{Solid-Phase Synthesis of COOH-Terminal Peptides}

COOH-terminal peptides of CXCL4 [CXCL4(47-70)] and CXCL9 [CXCL9(74-103), CXCL9(74-93), CXCL9(86-103)] were chemically synthesized using fluorenyl methoxycarbonyl (Fmoc) chemistry using an Activo-P11 automated synthesizer (Activotec, Cambridge, UK), as previously described (45). Part of the material was site-specifically biotinylated or fluorescently labeled at the $\mathrm{NH}_{2}$-terminus using biotin-p-nitrophenyl ester (Novabiochem, Darmstadt, Germany) or 5(6)-carboxytetramethylrhodamine (TAMRA; Merck Millipore, Darmstadt, Germany), respectively (42). After synthesis, intact synthetic peptides were purified and identified by mass spectrometry (Amazon SL or Amazon Speed ETD ion trap, Bruker, Bremen, Germany).

\section{Isothermal Fluorescence Titration (IFT)}

To study the interaction between CXCL9(74-93) and GAGs, titration experiments were performed as described by Gerlza et al. (46) using TAMRA-labeled synthetic CXCL9(74-93), TAMRAlabeled synthetic CXCL9(74-103), HS (Iduron BN1, Manchester, $\mathrm{UK}$ ), low molecular weight heparin (LMWH; Iduron BN5), and chondroitin sulfate (CS; Carbosynth, Compton, UK).

\section{Binding of $\mathrm{COOH}-$ Terminal Peptides to Cellular GAGs and Competition with CXCL8}

Binding of biotinylated CXCL9(74-103) and CXCL9(74-93) to $\mathrm{CHO}$ cells was assessed by flow cytometry as recently described (42). Briefly, cells were detached with phosphate-buffered saline (PBS) with $0.02 \%$ ethylenediaminetetraacetic acid (EDTA) and incubated with $\mathrm{NH}_{2}$-terminally biotinylated peptides. Subsequently, cells were incubated with streptavidin-allophycocyanin (BD Biosciences, San Jose, CA, USA) and analyzed by flow cytometry (FACSCalibur, BD Biosciences). To confirm inhibition of sulfation of cellular GAGs, part of the cells were stained with a mouse monoclonal anti-human HS antibody (Immunosource, Schilde, Belgium) and a secondary phycoerythrin-labeled goat anti-mouse antibody (BD Biosciences). Finally, cells were analyzed by flow cytometry. Analogously, binding of $100 \mathrm{nM}$ biotinylated CXCL8 in the presence or absence of CXCL9(74-103) or CXCL9(74-93) was compared on CHO cells.

\section{Competition of $\mathrm{COOH}-$ Terminal Peptides for Binding of Chemokines to GAGs}

The ability of the COOH-terminal peptides of CXCL9 and CXCL4 to compete for GAG binding with the inflammatory chemokines CXCL8 and CXCL1 was evaluated on heparinbinding plates [BD Biosciences or produced by Jason Whittle (School of Engineering/Future Industries Institute, University of South Australia, Australia)] (42, 47). In brief, GAGs (heparin, $\mathrm{HS}$, and CS; Iduron; $25 \mu \mathrm{g} / \mathrm{ml}$ ) were coated overnight at room temperature. Dilutions of COOH-terminal CXCL9 or CXCL4 peptide combined with recombinant human CXCL8(1-77) or recombinant murine CXCL1(1-72) (Peprotech, Rocky Hill, NJ, USA) were added in duplicate and incubated for $2 \mathrm{~h}$ at $37^{\circ} \mathrm{C}$. Subsequently, bound CXCL8 or CXCL1 was detected with biotinylated polyclonal rabbit anti-human CXCL8 or biotinylated polyclonal goat anti-mouse CXCL1 (Peprotech) and horse radish peroxidase-labeled streptavidin. Finally, the peroxidase activity was quantified at $450 \mathrm{~nm}$.

\section{CXCL8-Induced Migration of Neutrophils In Vivo}

In vivo neutrophil extravasation to the peritoneal or the knee cavity was examined, respectively, by intraperitoneal or intraarticular injection, of endotoxin-free recombinant CXCL8(1-77) (PeproTech) or vehicle (PBS) in female NMRI or C57BL/6 mice, as described previously $(42,48)$. Simultaneously, synthetic CXCL9 peptide was co-injected either intraperitoneally or injected intravenously. After $2 \mathrm{~h}$ (peritoneal cavity) or $3 \mathrm{~h}$ (knee cavity), mice were sacrificed. The peritoneal cavity was washed with saline enriched with $2 \%$ FCS and $20 \mathrm{U} / \mathrm{ml}$ heparin and total leukocyte counts were determined. For the preparation of cytospins, $10^{5}$ cells were used and absolute number and percentage of neutrophils in the lavages were determined in duplicate independently by two researchers by differential microscopic counting. The cells present in the tibiofemoral articulation were harvested by washing the cavity with $10 \mu \mathrm{l}$ of $3 \%(\mathrm{w} / \mathrm{v})$ bovine serum albumin in PBS and diluted in $90 \mu \mathrm{l}$ of $3 \%(\mathrm{w} / \mathrm{v})$ bovine serum albumin in PBS. The number of total leukocytes was determined by counting leukocytes in a Neubauer chamber after staining with Turk's solution. Differential counts were obtained from cytospin preparations by evaluating the percentage of each leukocyte type on a slide stained with May-Grunwald-Giemsa solution.

Intravenously injected fluorescent CXCL9(74-103) was detected in plasma after different time intervals by spectrofluorometric 
analysis and quantified against murine plasma spiked with known concentrations of the fluorescent peptide.

\section{MSU Crystal-Induced Gout in Mice}

Monosodium urate crystals were prepared as described previously $(42,49)$ and were injected $(100 \mu \mathrm{g}$ in $10 \mu \mathrm{l})$ in the tibiofemoral knee joint of $\mathrm{C} 57 \mathrm{Bl} / 6$ mice. A group of mice received CXCL9 peptide or vehicle intravenously and the cells present in the tibiofemoral articulation were harvested $3 \mathrm{~h}$ after MSU crystal administration. The total and differential leukocyte counts were determined.

\section{In Vivo Neutrophil Recruitment into the Cremaster Muscle}

Mice were anesthetized by intraperitoneal injection of $200 \mathrm{mg} / \mathrm{kg}$ ketamine (Bayer Inc. Animal Health) and $10 \mathrm{mg} / \mathrm{kg}$ xylazine (Bimeda-MTC). After anesthesia, the right jugular vein was cannulated for maintenance of anesthesia and to permit the delivery of the fluorescence-labeled antibodies. Mice were injected intravenously (via jugular vein) with either saline or CXCL9(74103) 5 min prior to an intrascrotal injection of 1 or $3 \mu \mathrm{g}$ CXCL8. The animals were placed on a water-heated operating table to maintain body temperature at $\sim 37^{\circ} \mathrm{C}$. The depth of anesthesia was controlled by regularly monitoring peripheral reflexes. The cremaster muscle was prepared as previously described (50). Briefly, the muscle was dissected free from other tissues and opened longitudinally with cautery. The muscle was held flat on a cover slip by attaching five sutures in the corner of the tissue and the tissue was then constantly superperfused $(1 \mathrm{ml} / \mathrm{min})$ with pre-warmed bicarbonate buffered saline ( $\mathrm{pH} 7.4$ ), throughout the experiment. Neutrophils were stained by intravenous injected anti-Ly6G-A647 home labeled antibodies (anti-Ly6G, clone $1 \mathrm{~A} 8$, was purchased from BioLegend and coupled to Alexa647 with the ThermoFisher protein labeling kit). In experiments in which unlabeled CXCL9(74-103) was used (evaluation of neutrophil adherence), neutrophils were labeled with PE-conjugated anti-Ly6G antibodies (eBiosciences) and endothelium with anti-CD31-A647 antibodies (BD Biosciences and coupled to Alexa647 with the ThermoFisher protein labeling kit). Single unbranched cremasteric venules with a diameter of $\sim 25-40 \mu \mathrm{m}$ were selected and their blood flow was recorded during a $5 \mathrm{~min}$ period. Spinning disk confocal intravital microscopy was performed using an Olympus BX51W1 (Olympus, Center Valley, PA, USA) upright microscope equipped with a $20 \times / 0.95$ XLUM Plan Fl water immersion objective. The microscope was equipped with a confocal light path (WaveFx, Quorum, Guelph, ON, Canada) on a Yokogawa CSU-10 head (Yokogawa Electric Corporation, Tokyo, Japan). Sensitivity settings were maintained at the same level for all experiments. A $512 \times 512$ pixel back-thinned EMCCD camera (C9100-13, Hamamatsu, Bridgewater, NJ, USA) was used for fluorescence detection. Volocity Acquisition software (Improvision Inc., Lexington, MA, USA) was used to drive the confocal microscope. Images captured using the spinning disk were processed and analyzed in Volocity 4.20. Periods of $5 \mathrm{~min} /$ field of view were recorded at 45, 60, and $90 \mathrm{~min}$ after CXCL8 administration. A neutrophil was considered to be adherent if it remained stationary for at least $30 \mathrm{~s}$, and total neutrophil adhesion was quantified as the number of adherent cells within a $100-\mu \mathrm{m}$ length of venule.

Alternatively, to evaluate the stability of the peptide on vascular endothelium, fluorescent CXCL9(74-103) was injected intravenously and visualized by intravital microscopy after different time intervals.

\section{Statistical Analysis}

All statistical analyses were performed using Statistica software version 13.1 (Dell, USA). The Mann-Whitney $U$-test was used to compare means or medians from independent groups $\left({ }^{*} p<0.05\right.$; $\left.{ }^{* *} p<0.01 ;{ }^{* * *} p<0.005\right)$.

\section{RESULTS}

\section{Chemical Synthesis and Labeling of CXCL9(74-103) and CXCL9(74-93)}

The highly cationic COOH-terminal peptides of CXCL9, namely, CXCL9(86-103), CXCL9(74-103), and CXCL9(74-93), were chemically synthesized, deprotected, and purified by RP-HPLC to evaluate their biological function (Table 1). Part of the peptides was site-specifically biotinylated or fluorescently labeled at the $\mathrm{NH}_{2}$-terminus. The $M_{\mathrm{r}}$ of the unlabeled and labeled purified synthetic peptides was confirmed by ion trap mass spectrometry. Figure 1 shows the mass spectra of CXCL9(74-93), $\mathrm{NH}_{2}-$ terminally biotinylated CXCL9(74-93), and $\mathrm{NH}_{2}$-terminally TAMRA-labeled CXCL9(74-93). The experimentally determined $M_{\mathrm{r}}$ corresponded to the theoretical $M_{\mathrm{r}}$ of 2,460.1, 2,686.4, and 2,871.5 for CXCL9(74-93), biotin-CXCL9(74-93), and TAMRACXCL9(74-93), respectively. In addition, a COOH-terminal peptide of CXCL4, namely, CXCL4(47-70), was chemically synthesized and purified (51).

\section{Interaction of CXCL9(74-93) with Soluble and Cellular GAGs}

To obtain more insight in the contribution of the unique $\mathrm{COOH}$ terminal region of CXCL9 and in the specificity of CXCL9-derived peptides for different GAGs, the affinity of CXCL9(74-93)

TABLE 1 | Overview of the amino acid sequence of the COOH-terminal peptides of CXCL9 and CXCL4 synthetized to investigate their glycosaminoglycan-binding affinity and their anti-inflammatory function.

\begin{tabular}{|c|c|c|}
\hline Peptide & Amino acid sequence & $M_{\mathrm{r}}$ (Da) \\
\hline CXCL9(74-103) & ${ }_{74}{ }_{\mathrm{KKKQKNGKKHQKKKVLKVRKSQRSSRQKKTT}}{ }_{103}$ & , \\
\hline CXCL9(74-93) & 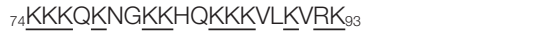 & \\
\hline CXCL9(86-103) & ${ }_{86} \mathrm{KKVLKVRKSQRSRQKKTT_{103 }}$ & $2,199.7$ \\
\hline CXCL4(47-70) & ${ }_{47} \mathrm{NGRKICLDLQAPLYKK}$ KIIKKLLES ${ }_{70}$ & 2,785 \\
\hline $\begin{array}{l}\text { Biotin- } \\
\text { CXCL9(74-93) }\end{array}$ & 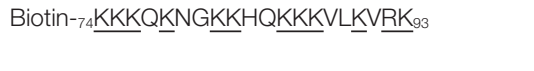 & 2686 \\
\hline $\begin{array}{l}\text { TAMRA- } \\
\text { CXCL9(74-93) }\end{array}$ & 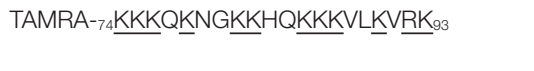 & 371 \\
\hline $\begin{array}{l}\text { Biotin- } \\
\text { CXCL9(74-103) }\end{array}$ & 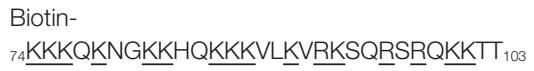 & 3,887 \\
\hline $\begin{array}{l}\text { TAMRA- } \\
\text { CXCL9(74-103) }\end{array}$ & $\begin{array}{l}\text { TAMRA- } \\
{ }_{74}{ }_{\text {KKKQKKNGKKHQKKKVLKV KRKSQRSSRQKKTT }}\end{array}$ & 4,072 \\
\hline
\end{tabular}

The amino acid sequence and the $M_{r}$ are listed. For clarity, basic amino acids were underlined. 

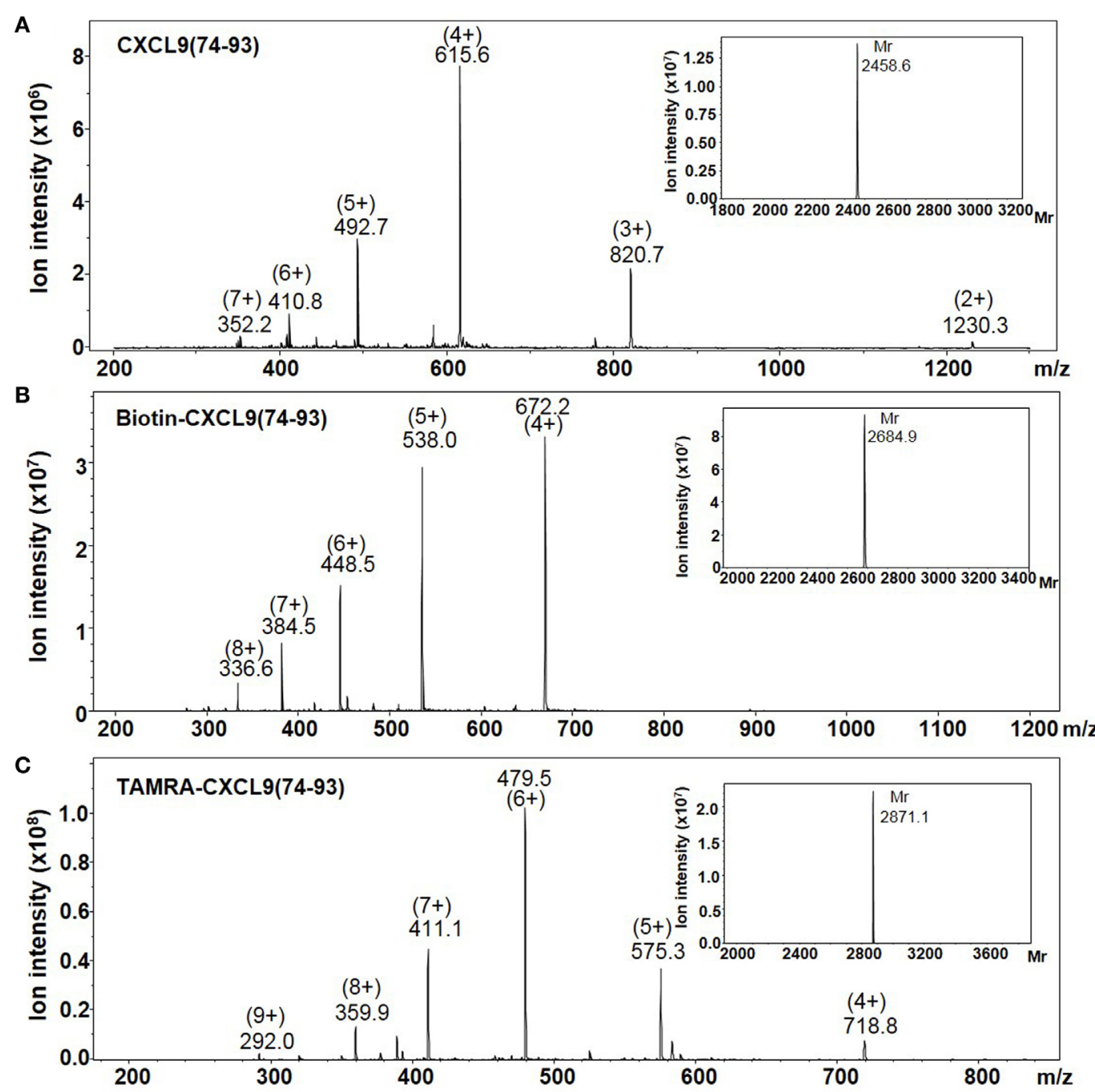

FIGURE 1 | The averaged mass spectra of CXCL9(74-93) peptides. The COOH-terminal peptides CXCL9(74-93), NH and $\mathrm{NH}_{2}$-terminally TAMRA-labeled CXCL9(74-93) were chemically synthesized based on Fmoc-chemistry. The intensity of the detected ions in function of their specific mass/charge ( $\mathrm{m} / \mathrm{z}$ ) ratio is shown for purified CXCL9(74-93) (A), $\mathrm{NH}_{2}$-terminally biotinylated CXCL9(74-93) (B), and $\mathrm{NH}_{2}$-terminally biotinylated TAMRAlabeled CXCL9(74-93) (C). In order to calculate the relative molecular mass $\left(M_{r}\right)$ of the proteins corresponding to the indicated ions, Bruker deconvolution software was used. The experimentally determined $M_{\mathrm{r}}$ of the peptides are shown as inserts on the upper right of the averaged mass spectra.

for LMWH, HS, and CS was determined by IFT. The affinity ( $K_{\mathrm{D}}$ value) of CXCL9(74-93) for LMWH, namely, $63 \pm 13 \mathrm{nM}$, was comparable to the previously reported $K_{\mathrm{D}}$ for LMWH of the longer CXCL9(74-103) peptide (61 nM) (42). A biphasic binding isotherm was obtained when titrating CXCL9(74-93) with HS, indicating more than one binding site for the peptide on this GAG. Fitting only the initial high-affinity phase, a $K_{\mathrm{D}}$ value of $1 \mathrm{nM}$ for $\mathrm{HS}$ was obtained. In contrast to the comparable $K_{\mathrm{D}}$ values on LMWH, CXCL9(74-103) showed about fourfold higher affinity for CS $(68 \pm 4.6 \mathrm{nM})$ compared to CXCL9(74-93) $(296 \pm 19 \mathrm{nM})$.

Because binding of the peptides to cellular GAGs is physiologically more relevant, binding of biotinylated CXCL9(74-103) and CXCL9(74-93) to CHO cells was evaluated by flow cytometric analysis. Figure 2A shows dose-dependent binding of the CXCL9 peptides to CHO cells. Although CXCL9(74-93) and CXCL9(74103) bound with comparable affinity to LMWH, CXCL9(74-93) displayed lower affinity to cellular GAGs. To ensure that binding was GAG-mediated, $\mathrm{CHO}$ cells were treated with $\mathrm{NaClO}_{3}$ to reduce the sulfation of GAGs. Measuring HS expression with a specific anti-HS antibody provides an indication for the total GAG expression level, as HS is the most relevant and abundant GAG on CHO and endothelial cells (52). Treatment of the CHO cells with $100 \mathrm{mM} \mathrm{NaClO}_{3}$ significantly reduced the expression of HS with $71.4 \%$ as evaluated by flow cytometry (data not shown) and consequently the binding of CXCL9(74-93) (Figure 2B).

\section{CXCL9(74-93) Competes with CXCL8 for Binding to Heparin or Cellular GAGs}

As recently described, CXCL9(74-103) more potently competes with CXCL8 for binding to heparin than CXCL9(74-103) missing 5 to $12 \mathrm{NH}_{2}$-terminal residues, stressing the importance of amino acids 74-78 for heparin binding (42). To further investigate the 


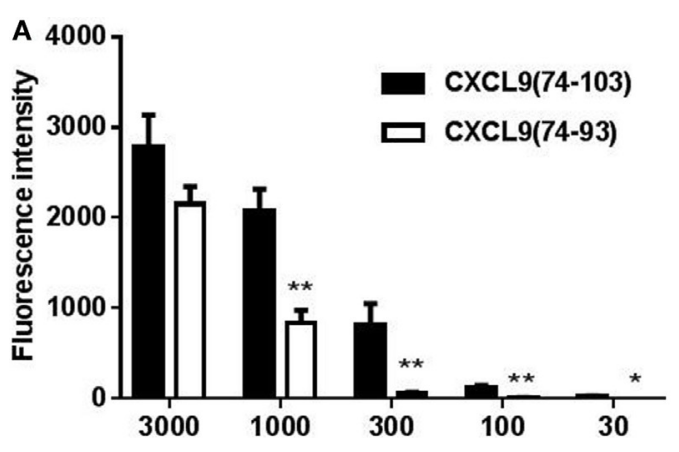

B Concentration biotinylated CXCL9 peptide (nM)

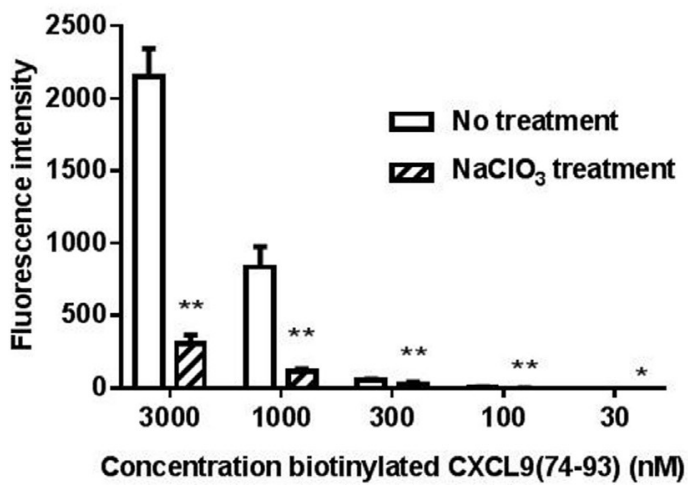

FIGURE 2 | CXCL9(74-93) interacts with cellular glycosaminoglycans (GAGs). The interaction of the $\mathrm{COOH}$-terminal CXCL9 peptides with Chinese hamster ovary (CHO) cells was assessed by flow cytometric analysis. (A) $\mathrm{CHO}$ cells were treated with dilutions of $\mathrm{NH}_{2}$-terminally biotinylated CXCL9(74-103) and CXCL9(74-93), which were detected by streptavidinallophycocyanin. (B) To ensure that the binding of CXCL9(74-93) was GAG-mediated, $\mathrm{CHO}$ cells were treated with sodium chlorate $\left(\mathrm{NaClO}_{3}\right)$ to reduce the sulfation of GAGs. Binding of biotinylated CXCL9(74-93) to cells, treated or untreated with $\mathrm{NaClO}_{3}$, was detected by streptavidinallophycocyanin. The mean (+SEM) fluorescence intensity of bound biotinylated CXCL9 peptides to $\mathrm{CHO}$ cells is indicated on the $y$-axis $(n \geq 4)$. A statistical comparison to evaluate the binding of biotinylated peptides on CHO cells [compared to the corresponding concentration of CXCL9(74-103) (A) or to the binding to cells not treated with $\mathrm{NaClO}_{3}$ (B)] was performed using the Mann-Whitney U-test $\left({ }^{*} p<0.05 ;{ }^{* *} p<0.01\right)$.

role of the COOH-terminal amino acids, the ability of CXCL9 (74-93) to inhibit binding of chemokines to heparin and HS was evaluated. CXCL9(74-93) and CXCL9(74-103) together with a $\mathrm{COOH}$-terminal peptide of one of the strongest GAG-binding chemokines, namely, CXCL4(47-70), were compared in an ELISAlike assay to compete with CXCL8 for heparin binding. As evidenced in Figure 3, CXCL9(74-93) competed with CXCL8 for heparin binding with a similar potency as CXCL9(74-103) thereby stressing the importance of amino acids 74-93. For both COOH-terminal CXCL9 peptides, a 10-fold molar excess compared to CXCL8 resulted in a 50\% reduction of CXCL8 binding to heparin (Figure 3A). Recently, it has been shown that CXCL4 (47-70) binds dose-dependently to GAGs on CHO cells with about fivefold lower affinity than CXCL9(74-103) (42). Indeed, also in the ELISA-like heparin-binding assay, CXCL4(47-70) was a less

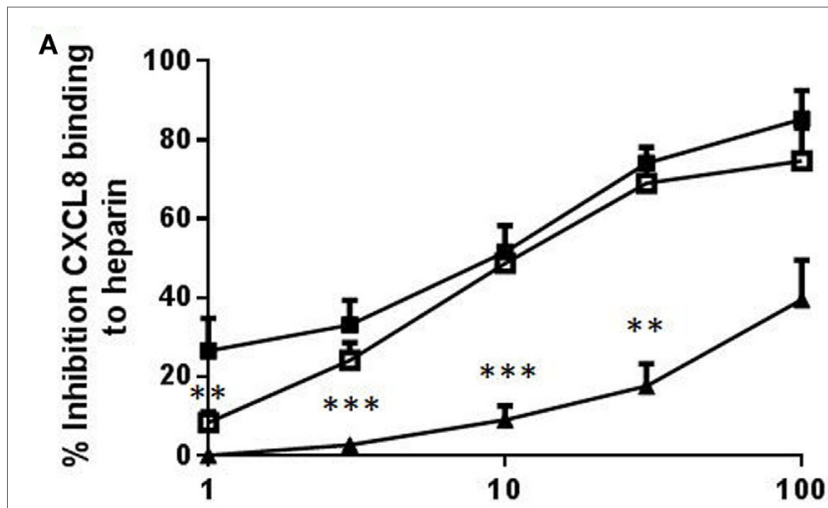

B Molar excess of COOH-terminal peptide

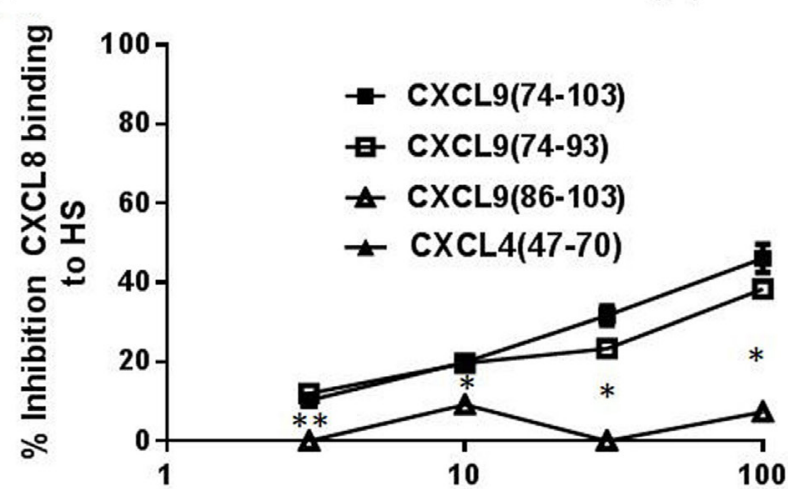

C

Molar excess of $\mathrm{COOH}$-terminal peptide

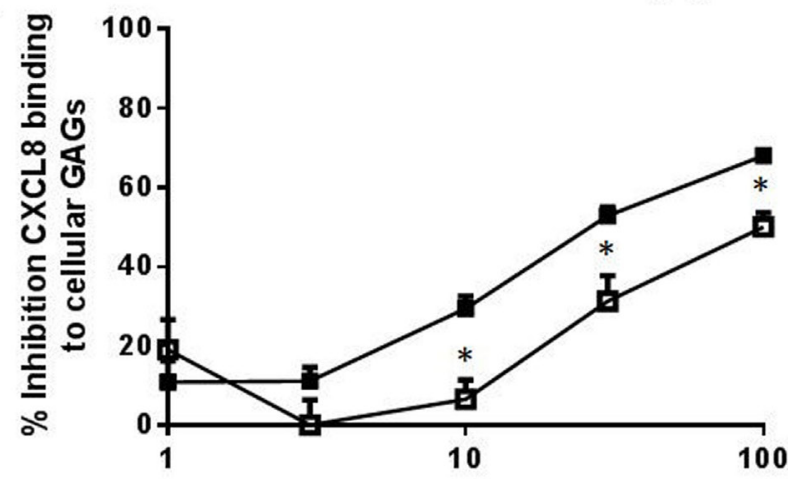

Molar excess of COOH-terminal peptide

FIGURE 3 | CXCL9(74-93) competes with CXCL8 for binding to heparin, heparan sulfate (HS), and cellular glycosaminoglycans (GAGs). Competition between CXCL8 and COOH-terminal CXCL9 or CXCL4 peptides for binding to immobilized heparin (A) or HS (B) and to Chinese hamster ovary (CHO) cells (C) was performed. (A) and (B) CXCL8(1-77) (0-300 nM) was added to heparin-coated or HS-coated 96-well plates in the presence or absence of the indicated excess of $\mathrm{COOH}$-terminal peptide

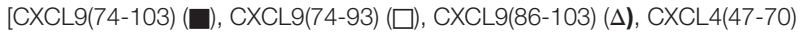
(4)]. Bound CXCL8 was detected with biotinylated anti-human CXCL8 antibodies. (C) Binding of $\mathrm{NH}_{2}$-terminally biotinylated CXCL8(1-77) (300 nM) to $\mathrm{CHO}$ cells in the presence or absence of an excess CXCL9 peptide was detected by streptavidin-allophycocyanin and flow cytometry. The mean $( \pm$ SEM) percentage inhibition of binding of CXCL8(1-77) to heparin, HS or cellular GAGs is indicated on the $y$-axis $(n \geq 4)$. Statistical comparison of the different competitors with CXCL9(74-103) was performed using the MannWhitney U-test $\left({ }^{*} p<0.05\right)$. 
potent competitor of CXCL8 binding than the CXCL9 peptides. A more than 100-fold molar excess of CXCL4(47-70) was needed to achieve a $50 \%$ reduction of CXCL8 binding. On HS-coated plates, CXCL9(74-93) and CXCL9(74-103) were equally efficient in inhibiting CXCL8 binding (Figure 3B), in contrast to the poorly competing CXCL9(86-103). Also on CHO cells, CXCL9(74-93) could inhibit the binding of biotinylated CXCL8 to cellular GAGs by $31 \%$ in the presence of a 30 -fold excess of CXCL9(74-93) (Figure 3C). A 100-fold excess of CXCL9(74-93) resulted in 50\% inhibition. On the other hand, a 30-fold excess of CXCL9(74-103) could inhibit the binding of CXCL8 by $53 \%$.

\section{CXCL9 Peptides Inhibit CXCL8- and MSU Crystal-Induced Neutrophil Recruitment In Vivo}

Recently, it was shown that CXCL9(74-103) could inhibit the neutrophil chemotactic activity of CXCL8 in vivo when CXCL8 was injected into the tibiofemoral articulation of C57BL/6 mice (42). To confirm this inhibition of CXCL8-induced neutrophil recruitment by CXCL9(74-103) in another body compartment, $1 \mu \mathrm{g}$ of CXCL8 was injected intraperitoneally in NMRI mice. Injection of CXCL8 $(1 \mu \mathrm{g})$ resulted in significant neutrophil migration to the peritoneal cavity, raising the absolute number and percentage of neutrophils in the peritoneal cavity to about $142 \times 10^{4}$ neutrophils $( \pm 15 \%)$ compared to the saline-injected group $\left(21 \times 10^{4}\right.$ neutrophils $)$. Concomitant intraperitoneal injection of $108 \mu \mathrm{g}$ CXCL9(74-103) significantly reduced the potency of CXCL8 to induce neutrophil extravasation (Figure 4A). Indeed, upon co-injection of $108 \mu \mathrm{g}$ CXCL9(74-103), the neutrophil accumulation only increased to $45 \times 10^{4}$ neutrophils (or 6.6\%). In contrast, at lower doses tested, i.e., 12 and $36 \mu$ g, CXCL9(74-103) failed to reduce CXCL8-induced neutrophil recruitment. As it could be expected based on the heparin-binding assays conducted before (42), $108 \mu \mathrm{g}$ intraperitoneally injected CXCL9(86-103) did not inhibit CXCL8-induced neutrophil migration (data not shown). Also intravenous injection of CXCL9(74-103) significantly reduced neutrophil migration toward intraperitoneally injected CXCL8 from $148 \times 10^{4}$ neutrophils $(16.5 \%)$ to $81 \times 10^{4}$ neutrophils $(10.1 \%)$ (Figure $\left.4 \mathrm{~B}\right)$. The lower doses of CXCL9(74-103) tested were not able to reduce the neutrophil migration significantly, although a trend toward a lower neutrophil influx was observed upon concomitant intravenous injection of $36 \mu \mathrm{g}$ CXCL9(74-103). In addition, the inhibitory potential of CXCL9(74-93) was also evaluated in this in vivo model. Figure 4C shows that CXCL9(74-93) is an equally potent inhibitor of CXCL8 than CXCL9(74-103). Intravenous injection of $66 \mu \mathrm{g}$ CXCL9(74-93), an equal molar amount compared to $108 \mu \mathrm{g}$ CXCL9(74-103), significantly reduced the CXCL8-induced neutrophil migration to the peritoneum from $192 \times 10^{4}$ neutrophils (19\%) to $65 \times 10^{4}$ neutrophils $(8.25 \%)$. Also neutrophil extravasation to the joint was strongly reduced after intravenous injection of $66 \mu \mathrm{g}$ CXCL9(74-93) from $13.3 \times 10^{3}$ neutrophils $(60.5 \%)$ to $0.67 \times 10^{3}$ neutrophils (17.5\%) (Figure 5).

Interestingly and in contrast to CXCL9(74-103) (42), CXCL9(74-93) could not inhibit MSU crystal-induced neutrophil migration to the joint (Figure 5). Therefore, the potency of different CXCL9 peptides to compete with chemokines for GAG binding was investigated in more detail. Since after injection of MSU crystals in the knee cavity the presence of the murine CXCR2 ligand CXCL1 is important for neutrophil migration (49), competition of CXCL9 peptides with CXCL1 for binding to HS was evaluated. Figure 6A demonstrates that CXCL9(7493) is a less potent competitor than CXCL9(74-103) for CXCL1 binding to HS. A threefold molar excess of CXCL9(74-103) compared to CXCL1 results in $43 \%$ reduction of CXCL1 binding to HS, whereas a 10-fold molar excess of CXCL9(74-93) only results in 39\% reduction. In contrast, CXCL9(86-103) was not able to inhibit the interaction between CXCL1 and HS. Since CS is generally found in connective tissues, such as cartilage, skin, tendons, and ligaments $(53,54)$, the ability of CXCL9 peptides

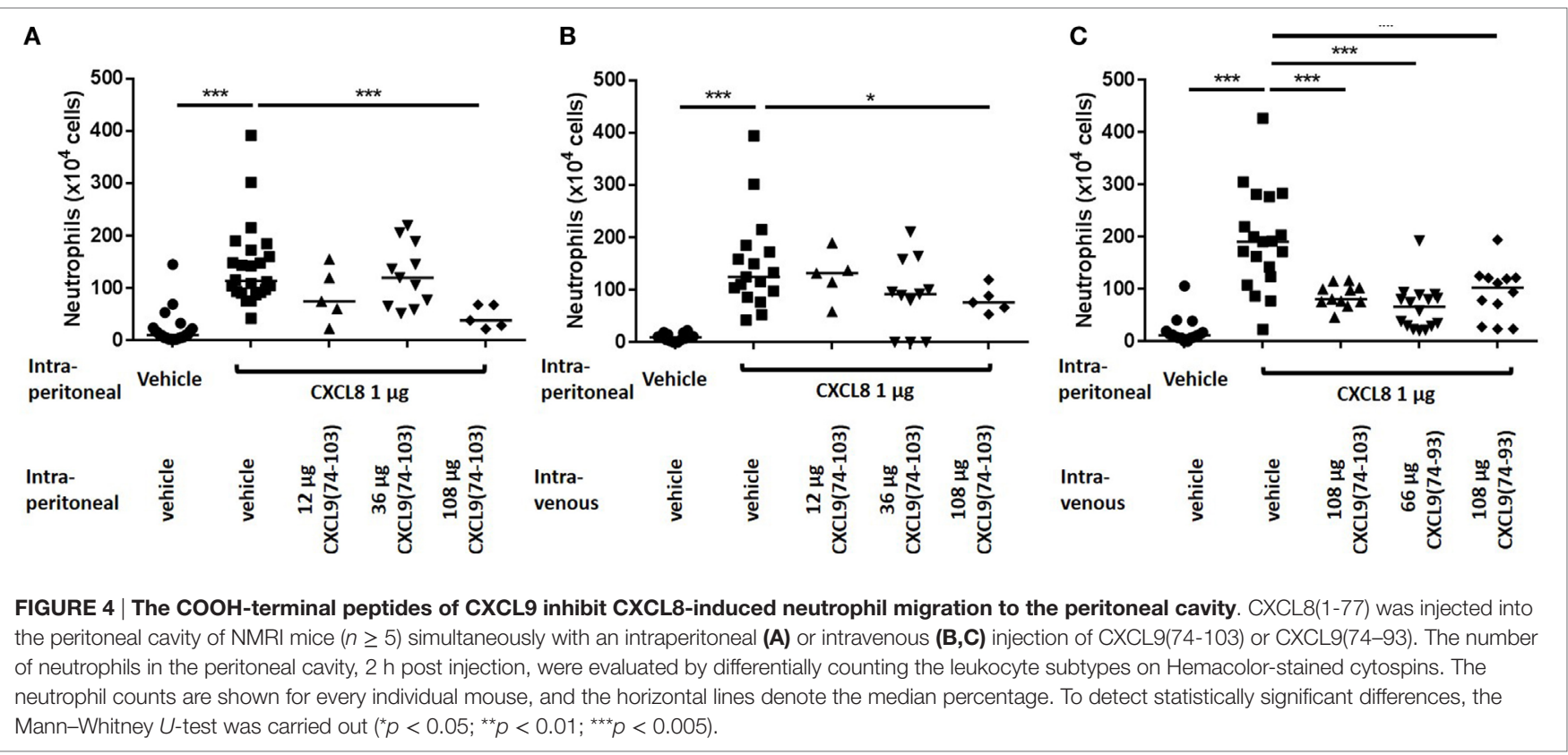


A

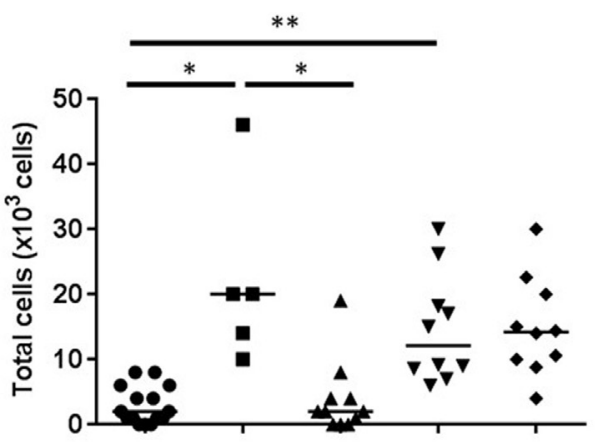

B

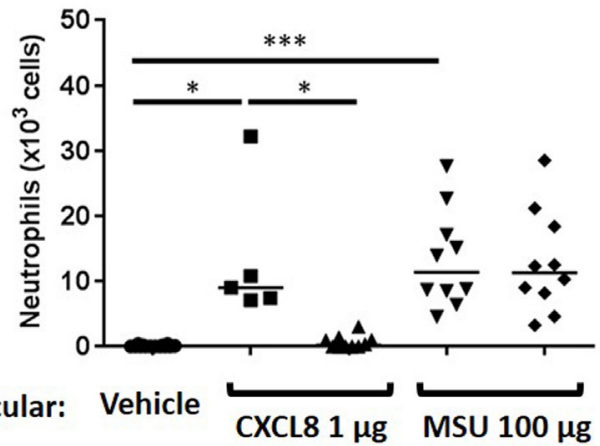

Intra-articular: Vehicle

Intravenous:

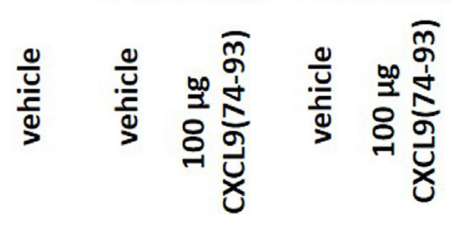

FIGURE 5 | CXCL9(74-93) inhibits CXCL8-induced but not monosodium urate (MSU) crystal-induced neutrophil migration to the knee cavity. CXCL8(1-77) $(1 \mu \mathrm{g})$ or MSU crystals $(100 \mu \mathrm{g})$ were injected into the tibiofemoral articulation of C57BL/6 mice $(n \geq 5)$. Simultaneously, $66 \mu g$ of CXCL9(74-93) was injected intravenously and $3 \mathrm{~h}$ post injection the number of total cells $(\mathbf{A})$ and neutrophils $(\mathbf{B})$ were evaluated by washing the cavity and differentially counting the leukocyte subtypes on May-GrunwaldGiemsa-stained cytospins. The total numbers of leukocytes and neutrophils are shown for every individual mouse, and the horizontal lines denote the median number of cells. To detect statistically significant differences, the Mann-Whitney $U$-test was carried out $\left({ }^{\star} p<0.05 ;{ }^{* \star} p<0.01 ;{ }^{\star \star \star} p<0.005\right)$.

to compete with CXCL1 for binding to CS was evaluated also. Again, three times more CXCL9(74-93) than CXCL9(74-103) was needed to achieve the same reduction of CXCL1 binding to CS (Figure 6B). In addition, the maximum inhibition of CXCL1 binding achieved by competition with CXCL9(74-103) (72\% for HS and $63 \%$ for CS) was higher than the maximum inhibition achieved by competition with CXCL9(74-93) (52\% for HS and CS).

\section{CXCL9(74-103) Binds to Endothelial Cells and Prevents Adhesion of Peripheral Mononuclear Cells in the Murine Cremaster Muscle Model}

To evaluate the binding of CXCL9(74-103) to the endothelium in vivo, the peptide was site-specifically fluorescently (TAMRA-) labeled at the $\mathrm{NH}_{2}$-terminus avoiding modification of lysine side chains which are known to be important for interaction with GAGs. Binding of TAMRA-CXCL9(74-103) to endothelial cells was evaluated in the murine cremaster muscle model. Fifty minutes after intravenous injection, the peptide was clearly present on the vascular surface of the endothelium (Figure 7). In circulation, only a fraction of the injected amount $(3 \%$ or $2 \mu \mathrm{g} / \mathrm{ml})$ of the TAMRA-labeled peptide was detected in the plasma 5 min after intravenous injection (assuming a blood volume of $3 \mathrm{ml}$ for the mice). Already $1 \mathrm{~h}$ after injection, no circulating peptide was detected in the plasma $(<240 \mathrm{ng} / \mathrm{ml})$. In addition, the effect of prior CXCL9(74-103) injection via the jugular vein on chemokine superperfusion of the cremaster muscle was analyzed. At different time intervals $(45,60$, and $90 \mathrm{~min})$ after CXCL8 addition to the cremaster muscle superperfusate, neutrophil-endothelial cell interactions were registered through intravital microscopy and the number of adherent neutrophils was quantified (Figure 8A). Intrascrotal injection of $1 \mu \mathrm{g}$ CXCL8 resulted in an increase in adherent neutrophils after $60 \mathrm{~min}$, whereas injection of $3 \mu \mathrm{g}$ CXCL8 already resulted in an increase after $45 \mathrm{~min}$. In both cases (1 and $3 \mu \mathrm{g}$ CXCL8), concomitant intravenous injection of $108 \mu \mathrm{g}$ CXCL9(74-103) reduced the adherence of neutrophils to the endothelium significantly (Figure 8B; Video S1 in Supplementary Material).

\section{DISCUSSION}

Directional leukocyte migration to specific primary, secondary, or tertiary lymphoid organs is important for normal functioning of our immune system. In addition, it is a crucial phenomenon to clear pathogens from sites of infection, to kill malignant cells, and to restore tissue damage. The interplay between adhesion molecules such as selectins and integrins, chemoattractants, and their receptors guides this process $(17,18,55,56)$. In order to prevent wash-out of chemokines from the surface of endothelial cells, chemokines can bind to negatively charged GAGs $(18,57,58)$. These GAGs are linear polysaccharides which consist of repeating disaccharide subunits and dependent on the subunit they will be classified into different classes, e.g., heparin, HS, and CS (59). Heparin consists of repeating glucuronic acid and $\mathrm{N}$-acetyl glucosamine residues and is highly sulfated with 80-90\% N-sulfated glucosamine units. In contrast, HS consists of iduronic acid and is less sulfated with only $30-60 \%$ of the glucosamine units being $\mathrm{N}$-sulfated. An extra level of complexity is the high degree of variations in GAG (e.g., HS) structures in different organs (60). It has been shown that chemokines localize within capillary venules in a GAG-dependent way to create a chemotactic gradient and destruction of these gradients results in abrogated directional migration of leukocytes $(12,13)$. Through interaction with GAGs chemokines can also form gradients in tissues along which leukocytes can migrate to the site of inflammation $(13,14)$. This interaction occurs between GAG-binding motifs in the chemokine and the sulfated domains in the GAG.

Three human chemokines, i.e., CXCL9, CXCL12 $\gamma$, and CCL21, possess an elongated $\mathrm{COOH}$-terminal tail which is highly positively charged. Linking the COOH-terminal tail of CCL21 to the 

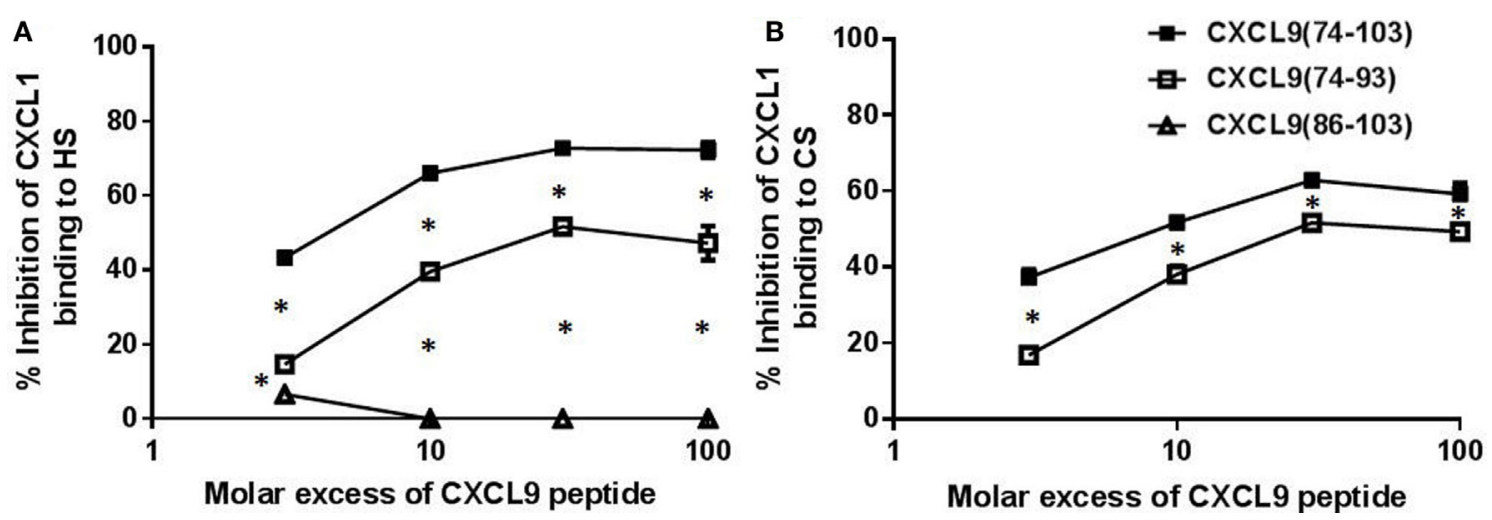

FIGURE 6 | CXCL9(74-93) is a less potent competitor for CXCL1 binding to glycosaminoglycans (GAGs). Competition between CXCL1 and COOHterminal CXCL9 peptides for binding to immobilized heparan sulfate (HS) (A) and chondroitin sulfate (CS) (B) was performed. Dilutions of CXCL1 were added to GAGs in 96-well plates in the presence or absence of the indicated excess of COOH-terminal peptide [CXCL9(74-103) ( $\square$ ), CXCL9(74-93) ( $\square$ ), CXCL9(86-103) ( $\Delta$ )]. Bound CXCL1 was detected with biotinylated polyclonal goat anti-mouse CXCL1 antibodies. The mean ( \pm SEM) percentage inhibition of CXCL1 binding to GAGs is indicated on the $y$-axis $(n \geq 3)$. Statistical comparison of the different competitors with CXCL9(74-103) was performed using the Mann-Whitney $U$-test.

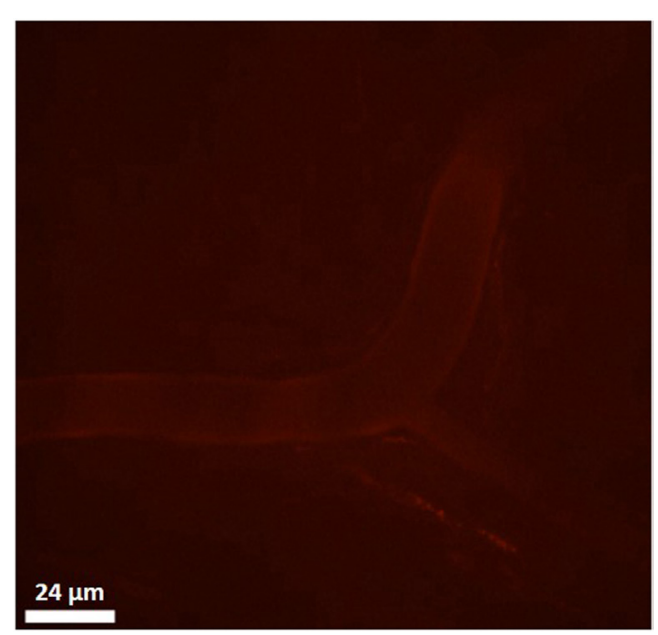

FIGURE 7 | Binding of TAMRA-labeled CXCL9(74-103) to the vascular surface of the endothelium. Binding of the TAMRA-labeled CXCL9(74103) to endothelial cells was evaluated in the murine cremaster muscle model. Fluorescent peptide $(100 \mu \mathrm{g})$ was injected intravenously and binding to the vascular surface of the endothelium was visualized by confocal in vivo imaging 50 min after injection.

related CCR7 ligand CCL19 enhanced its affinity for heparin (61). Cooperativity between CCL21 and other chemokines was shown to depend on this GAG-binding $\mathrm{COOH}$-terminal domain (62) and the COOH-terminal tail of CCL21 reduced its in vitro chemotactic potency in a $3 \mathrm{D}$ dendritic cell chemotaxis assay, but enhanced its efficiency to activate ERK1/2 signaling and $\beta$-arrestin recruitment (63). In addition, full-length CCL21 was shown to induce integrin-dependent dendritic cell spreading, polarization and haptotactic movement, whereas CCL21 missing the positively charged C-terminus induced non-adhesive and integrin-independent directional migration (64). Also CXCL12 $\gamma$ appeared to be a weaker chemoattractant than CXCL1 $2 \alpha$ in assays studying migration through uncoated chemotaxis membranes
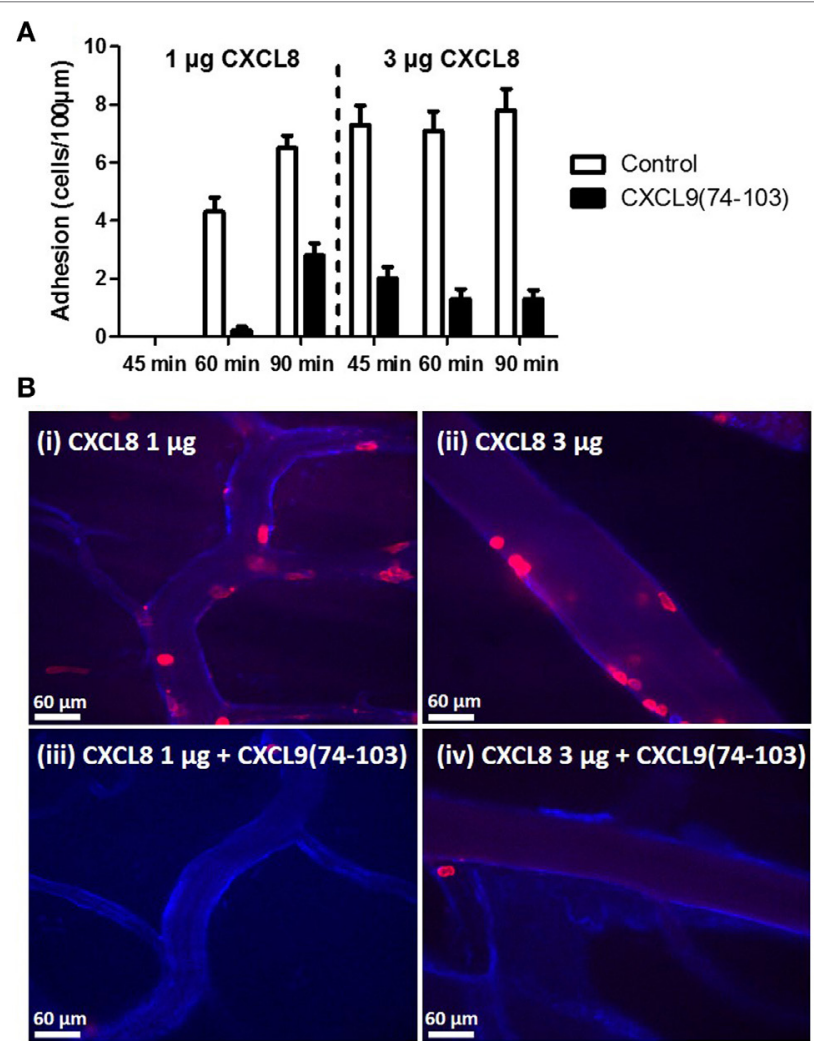

FIGURE 8 | CXCL9(74-103) inhibits adhesion of neutrophils in the murine cremaster muscle model. (A) Neutrophil adhesion to the endothelium in response to an intrascrotal injection of 1 or $3 \mu \mathrm{g} \mathrm{CXCL8}$ in the presence or absence of $108 \mu \mathrm{g}$ intravenously injected CXCL9(74-103) was quantified at different time points $(45,60$, and $90 \mathrm{~min})$. (B) The cremaster of mice was superfused with 1 (i and iii) or $3 \mu \mathrm{g}$ (ii and iv) of CXCL8 and endothelium was stained with anti-PECAM-1/CD31 antibody coupled to Alexa 647. The adhering neutrophils were visualized with an anti-Ly6G antibody conjugated to PE and quantified at 60 min post CXCL8 injection. In addition, mice were injected intravenously with either saline (i and ii) or CXCL9(74-103) (iii and iv) 5 min prior to the intrascrotal injection of CXCL8. 


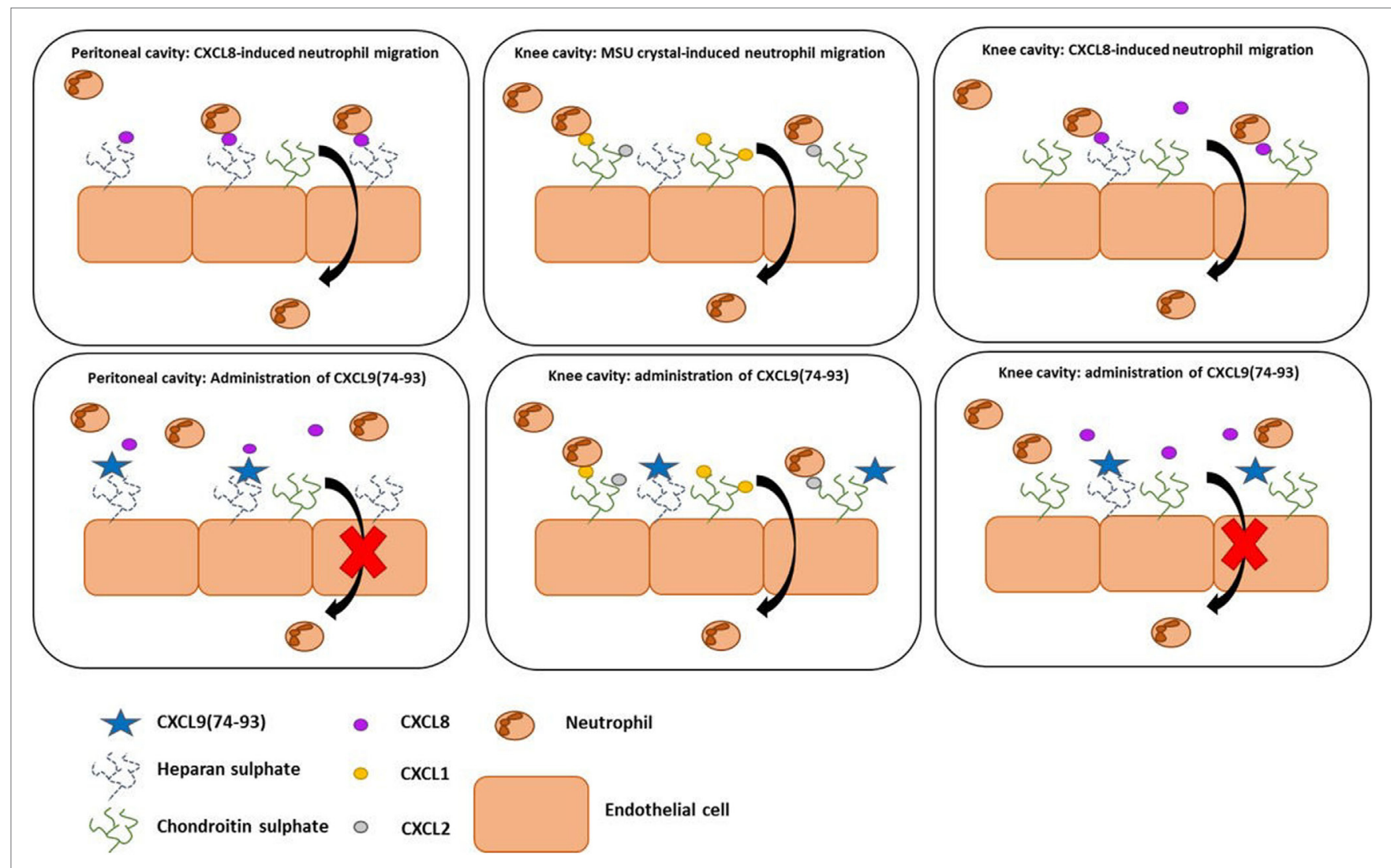

FIGURE 9 | The anti-inflammatory activity of CXCL9(74-93) in murine models of neutrophil migration. In the peritoneum, both CXCL9(74-93) and CXCL9(74-103) inhibit CXCL8-induced neutrophil migration. Because of the high affinity of both peptides for heparan sulfate (HS), it can be suggested that HS is important for the creation of a CXCL8-dependent chemotactic gradient in the peritoneum. In that way, the CXCL9 peptides compete with CXCL8 and inhibit neutrophil extravasation. Although chondroitin sulfate (CS) is most abundant in the articular cavity and the affinity of the peptides for CS is different, both peptides are able to inhibit CXCL8-induced neutrophil migration to the knee cavity. In the gout model, the lower efficiency of CXCL9(74-93) to inhibit CS binding of the induced murine chemokines does not prevent neutrophil migration.

(65). However, CXCL12 $\gamma$ attracted T cells through an endothelial layer. The highly charged COOH-terminal domain of CCL12 $\gamma$ was shown to interact with sulfotyrosines on CXCR4 thereby enhancing its affinity for the receptor but reducing the signal. HS was able to inhibit binding of CXCL12 $\gamma$ to sulfotyrosines of CXCR4 and converted CXCL12 $\gamma$ into a functional CXCR4 ligand. Recently, we identified natural forms of CXCL9 missing the $\mathrm{COOH}$-terminal domain that retained CXCR3 signaling potency (42).

In several inflammatory diseases, an enhanced expression of chemokines leads to the pathological and continuous accumulation of activated leukocytes in tissues and consequently tissue damage. Thus, a reduction of chemokine activity at sites of excessive inflammation is needed. Although a lot of efforts were invested in the development of small molecule chemokine receptor antagonists, since the discovery of chemokine receptors as members of the GPCR family about two decades ago, success stories are limited to a few drugs that entered the market (66). Recently, inhibition of chemokine-GAG interaction has been explored as a complementary alternative for chemokine receptor antagonists. Both modified chemokines with enhanced GAG interaction and reduced activity on GPCRs, and aptamers that interfere with chemokine-GAG binding have entered clinical development $(40,41)$. The COOH-terminal CXCL9 domain CXCL9(74-103) potently bound GAGs, competed for GAG binding with several chemokines and was able to inhibit CXCL8and MSU crystal-induced leukocyte migration to joints (42). In addition, the CXCL9(74-103) and COOH-terminal CXCL12 $\gamma$ peptides were able to inhibit viral infection of cells with dengue virus, herpes simplex virus-1 and respiratory syncytial virus due to competition with the viruses for GAG binding (43).

In this study, we investigated in detail the role of the $\mathrm{COOH}$ terminal part of CXCL9 for its affinity and specificity toward different GAGs. IFT showed that both $\mathrm{COOH}$-terminal peptides, i.e., CXCL9(74-103) and CXCL9(74-93), show high and comparable affinity for LMWH and HS. CXCL9(74-93), which contains the two $\mathrm{NH}_{2}$-terminal and crucial GAG-binding motifs of CXCL9(74-103), competed equally efficient with CXCL8 for binding to immobilized heparin and HS. However, the affinity for CS and the binding of CXCL9(74-93) to cellular GAGs on CHO cells is lower compared to CXCL9(74-103). This suggests that on the surface of $\mathrm{CHO}$ cells not only HS, but a mixture of 
different GAGs are expressed and are important for the binding of the COOH-terminal peptides. Analogously, CXCL9(74-93) is not able to compete with CXCL8 for binding to cellular GAGs to the same degree as CXCL9(74-103). Thus, the removal of the $10 \mathrm{COOH}$-terminal amino acids of CXCL9(74-103) results in a certain specificity toward LMWH and HS (and loss of CS binding). Previously, it has been described that the motifs BBXB and BBBXXB in proteins, in which $B$ represents a basic and $X$ represents any non-basic amino acid, are important for GAG binding (67). Both CXCL9(74-103) and CXCL9(74-93) contain the same GAG-binding motifs $\left(\mathrm{Lys}^{75}-\mathrm{Lys}^{78}\right.$ and $\mathrm{Lys}^{85}-\mathrm{Lys}^{90}$ ). However, CXCL9(74-93) lacks the remaining COOH-terminal amino acids. This modification influenced the interaction with GAGs, thereby indicating a certain degree of specificity of the peptides for different GAGs. It can be suggested that the change of GAG affinity and specificity between both peptides is due to the presence of a "reversed" GAG-binding domain (BXBB instead of $\mathrm{BBXB}$ ) in the $\mathrm{COOH}$-terminal region of CXCL9(74-103) between Arg-98 and Lys-101.

In view of the variation in GAG structures between different organs, we investigated the importance of chemokine-GAG interactions in the inflammatory response upon injection of CXCL8 or MSU crystals in different tissues, i.e., the peritoneal and/or knee cavity and the cremaster muscle. Although mice lack the gene for CXCL8, a strong neutrophilic inflammation can be induced when CXCL8 is administered in mice $(42,68)$. In addition, the capacity of CXCL9(74-93) to inhibit MSU crystal-induced neutrophil migration was assessed. Both upon intraperitoneal or intra-articular injection of CXCL8, concomitant injection of CXCL9(74-103) or CXCL9(74-93) was able to inhibit neutrophil-dependent inflammation. Our results also show that CXCL9(74-93), when given intravenously in equimolar concentrations, could inhibit CXCL8 activity in vivo with similar potency as CXCL9(74-103). On the contrary, CXCL9(74-93) was not able to inhibit neutrophil extravasation in the more complex and less chemoattractant-specific MSU crystal-induced gout model. This difference in anti-inflammatory activity can be explained in several ways (Figure 9). First, it is known that in the articular cavity CS is an abundant GAG, comprising 60-90\% of the GAG molecules $(69,70)$. Keeping in mind that CXCL9(74-93) binds with lower affinity to CS, it can be suggested that this peptide cannot compete with chemokines for binding to CS in the same way as CXCL9(74-103). Indeed, CXCL9(74-93) is a less potent competitor for CXCL1 binding to HS and CS (Figure 6), a previously reported major neutrophil chemoattractant in this gout model (49). Second, it is known that chemokines bind with different affinity and/or specificity to different GAGs $(71,72)$. In the gout model, the induced murine chemokines (CXCL1 and CXCL2 (49)) probably bind with different affinity or specificity to different GAGs in the murine knee cavity than human CXCL8. This would explain why a peptide with lower affinity for those GAGs cannot compete with the induced murine chemokines. In conclusion, both the affinity and the specificity of the peptides and the chemokines for different GAGs will determine whether competition can occur. Finally, we investigated whether the more potent CXCL9 (74-103) peptide could inhibit the activity of CXCL8 in the murine cremaster muscle model. In this model, CXCL8 was injected intrascrotally into the cremaster muscle to induce adhesion of neutrophils to the endothelium. Intravital microscopy of the muscle clearly shows that the fluorescent CXCL9 peptide binds to the endothelium. In this way, CXCL8 was not able to bind to GAGs and direct evidence was provided for lower adhesion of neutrophils to the endothelium.

Thus, overall we show that CXCL9(74-103) indeed inhibits neutrophil migration in vivo through interference with GAG interactions in three animal models and that shortening this CXCL9 from the $\mathrm{COOH}$-terminus increases its specificity for particular GAGs. Obtaining detailed knowledge on the specificity of these GAG-binding peptides is important for the development of lead molecules for the generation of therapeutics competing with active chemokines for GAG binding to avoid potential side effects.

\section{ETHICS STATEMENT}

Animal experiments at the Rega Institute for Medical Research, University of Leuven, were carried out in female adult NMRI mice, purchased from Elevage Janvier (Le Genest Saint Isle, France), in agreement with the Ethical Committee for Animal Care and Use of the KU Leuven and in adherence to the international guidelines for animal ethics and welfare. Mouse studies at the Federal University of Minas Gerais were performed in adult C57BL/6 mice. The experiments were approved by the Animal Ethical Committee of the Federal University of Minas Gerais. Mice were sacrificed by i.p. injection of an overdose of nembutal or ketamine $(150 \mathrm{mg} / \mathrm{kg})$ and xylazine $(20 \mathrm{mg} / \mathrm{kg})$ prior to the collection of joint lavages. For the intravital microscopy studies, male C57Bl/6J mice were purchased from Jackson Laboratories (Bar Harbor, ME, USA). Animals were maintained in a specific pathogen-free environment at the University of Calgary Animal Resource Centre. All experimental animal protocols were approved by the University of Calgary Animal Care Committee and were in compliance with the Canadian Council for Animal Care Guidelines.

\section{AUTHOR CONTRIBUTIONS}

VV, AM, EK, SS, and PP designed the study and VV, EK, SS, and $\mathrm{PP}$ wrote the paper. All authors analyzed and interpreted the data. VV, DB, RJ, BP, and NB performed the experiments. VV and PP synthetized and purified the CXCL9 peptides and performed mass spectrometry and GAG-binding assays. VV, AM, and NB were involved in the CXCL8-induced inflammation model in the peritoneum. BP, EK, and PK were involved in the cremaster muscle model. DB, RJ, FA, and MT were involved in the murine gout model. VV and AK were involved in the IFT measurements. All authors revised the work and approved the version to be published. 


\section{ACKNOWLEDGMENTS}

The authors would like to thank Jason Whittle (School of Engineering/Future Industries Institute, University of South Australia, Australia) for the heparin-binding plates.

\section{FUNDING}

This research was supported by the Interuniversity Attraction Poles Programme initiated by the Belgian Science Policy Office (I.A.P. Project 7/40), the Fund for Scientific Research of Flanders, the Brazilian National Council for Scientific and Technological Development (CNPq), the Concerted Research Actions of the Regional Government of Flanders (GOA/12/017). The Hercules Foundation of the Flemish Government funded the purchase of LC-MS/MS equipment (Contract AKUL/11/31). AM obtained a postdoctoral research scholarship of the FWO-Vlaanderen. EK was supported by a Marie Curie fellowship of the European Union (FP7-PEOPLE-2010-IOF, grant No. 273340), and currently

\section{REFERENCES}

1. Proost P, Struyf S, Loos T, Gouwy M, Schutyser E, Conings R, et al. Coexpression and interaction of CXCL10 and CD26 in mesenchymal cells by synergising inflammatory cytokines: CXCL8 and CXCL10 are discriminative markers for autoimmune arthropathies. Arthritis Res Ther (2006) 8:R107. doi:10.1186/ar1937

2. Grainger R, McLaughlin RJ, Harrison AA, Harper JL. Hyperuricaemia elevates circulating CCL2 levels and primes monocyte trafficking in subjects with inter-critical gout. Rheumatology (Oxford) (2013) 52:1018-21. doi:10.1093/ rheumatology/kes326

3. Brennan FM, Zachariae CO, Chantry D, Larsen CG, Turner M, Maini RN, et al. Detection of interleukin 8 biological activity in synovial fluids from patients with rheumatoid arthritis and production of interleukin $8 \mathrm{mRNA}$ by isolated synovial cells. Eur J Immunol (1990) 20:2141-4. doi:10.1002/eji.1830200938

4. Lindley IJ, Ceska M, Peichl P. NAP-1/IL-8 in rheumatoid arthritis. Adv Exp Med Biol (1991) 305:147-56. doi:10.1007/978-1-4684-6009-4_17

5. DeMarco D, Kunkel SL, Strieter RM, Basha M, Zurier RB. Interleukin-1 induced gene expression of neutrophil activating protein (interleukin-8) and monocyte chemotactic peptide in human synovial cells. Biochem Biophys Res Commun (1991) 174:411-6. doi:10.1016/0006-291X(91)91431-B

6. Endo H, Akahoshi T, Takagishi K, Kashiwazaki S, Matsushima K. Elevation of interleukin-8 (IL-8) levels in joint fluids of patients with rheumatoid arthritis and the induction by IL- 8 of leukocyte infiltration and synovitis in rabbit joints. Lymphokine Cytokine Res (1991) 10:245-52.

7. Baggiolini M, Dewald B, Moser B. Human chemokines: an update. Annu Rev Immunol (1997) 15:675-705. doi:10.1146/annurev.immunol.15.1.675

8. Rollins BJ. Chemokines. Blood (1997) 90:909-28.

9. Murphy PM, Baggiolini M, Charo IF, Hebert CA, Horuk R, Matsushima K, et al. International union of pharmacology. XXII. Nomenclature for chemokine receptors. Pharmacol Rev (2000) 52:145-76.

10. Bachelerie F, Ben-Baruch A, Burkhardt AM, Combadiere C, Farber JM, Graham GJ, et al. International Union of Basic and Clinical Pharmacology. [Corrected]. LXXXIX. Update on the extended family of chemokine receptors and introducing a new nomenclature for atypical chemokine receptors. Pharmacol Rev (2014) 66:1-79. doi:10.1124/pr.113.007724

11. Middleton J, Neil S, Wintle J, Clark-Lewis I, Moore H, Lam C, et al. Transcytosis and surface presentation of IL- 8 by venular endothelial cells. Cell (1997) 91:385-95. doi:10.1016/S0092-8674(00)80422-5

12. Massena S, Christoffersson G, Hjertstrom E, Zcharia E, Vlodavsky I, Ausmees N, et al. A chemotactic gradient sequestered on endothelial heparan sulfate induces directional intraluminal crawling of neutrophils. Blood (2010) 116:1924-31. doi:10.1182/blood-2010-01-266072 is supported by the National Science Centre of Poland (grant No. 2014/15/B/NZ6/02519). In addition, this work was supported by the Snyder Mouse Phenomics Resources Laboratory and Live Cell Imaging Facility, both of which were funded by the Snyder Institute for Chronic Diseases at the University of Calgary.

\section{SUPPLEMENTARY MATERIAL}

The Supplementary Material for this article can be found online at http://journal.frontiersin.org/article/10.3389/fimmu.2017.00530/ full\#supplementary-material.

\section{VIDEO S1 | Adhesion of neutrophils in the murine cremaster muscle} model is inhibited by a single injection of CXCL9(74-103). Adhesion of CXCL8 activated neutrophils to endothelium of the cremaster muscle vasculature. Mice were injected intravenously with either saline (controls; video I) or CXCL9(74-103) (video II) 5 min prior to an intrascrotal injection of $1 \mu \mathrm{g}$ of CXCL8. The adhering neutrophils were visualized (as shown in exemplary videos I and II) and quantified (Figure 7B) at 60 min post CXCL8 injection. The endothelium was stained with anti-PECAM-1/CD31 antibody coupled to Alexa 647 and neutrophils with anti-Ly6G antibody conjugated to PE. The scale bar indicates $60 \mu \mathrm{m}$.
13. Sarris M, Masson JB, Maurin D, Van der Aa LM, Boudinot P, Lortat-Jacob H, et al. Inflammatory chemokines direct and restrict leukocyte migration within live tissues as glycan-bound gradients. Curr Biol (2012) 22:2375-82. doi:10.1016/j.cub.2012.11.018

14. Weber M, Hauschild R, Schwarz J, Moussion C, de Vries I, Legler DF, et al. Interstitial dendritic cell guidance by haptotactic chemokine gradients. Science (2013) 339:328-32. doi:10.1126/science.1228456

15. Middleton J, Patterson AM, Gardner L, Schmutz C, Ashton BA. Leukocyte extravasation: chemokine transport and presentation by the endothelium. Blood (2002) 100:3853-60. doi:10.1182/blood.V100.12.3853

16. Ley K, Laudanna C, Cybulsky MI, Nourshargh S. Getting to the site of inflammation: the leukocyte adhesion cascade updated. Nat Rev Immunol (2007) 7:678-89. doi:10.1038/nri2156

17. Nourshargh S, Alon R. Leukocyte migration into inflamed tissues. Immunity (2014) 41:694-707. doi:10.1016/j.immuni.2014.10.008

18. Proudfoot AE, Handel TM, Johnson Z, Lau EK, LiWang P, Clark-Lewis I, et al. Glycosaminoglycan binding and oligomerization are essential for the in vivo activity of certain chemokines. Proc Natl Acad Sci U S A (2003) 100:1885-90. doi:10.1073/pnas.0334864100

19. Handel TM, Johnson Z, Crown SE, Lau EK, Proudfoot AE. Regulation of protein function by glycosaminoglycans - as exemplified by chemokines. Annu Rev Biochem (2005) 74:385-410. doi:10.1146/annurev.biochem.72.121801.161747

20. Johnson Z, Proudfoot AE, Handel TM. Interaction of chemokines and glycosaminoglycans: a new twist in the regulation of chemokine function with opportunities for therapeutic intervention. Cytokine Growth Factor Rev (2005) 16:625-36. doi:10.1016/j.cytogfr.2005.04.006

21. Campanella GS, Grimm J, Manice LA, Colvin RA, MedoffBD, Wojtkiewicz GR, et al. Oligomerization of CXCL10 is necessary for endothelial cell presentation and in vivo activity. J Immunol (2006) 177:6991-8. doi:10.4049/ jimmunol.177.10.6991

22. Severin IC, Gaudry JP, Johnson Z, Kungl A, Jansma A, Gesslbauer B, et al. Characterization of the chemokine CXCL11-heparin interaction suggests two different affinities for glycosaminoglycans. J Biol Chem (2010) 285:17713-24. doi:10.1074/jbc.M109.082552

23. Wang L, Fuster M, Sriramarao P, Esko JD. Endothelial heparan sulfate deficiency impairs L-selectin- and chemokine-mediated neutrophil trafficking during inflammatory responses. Nat Immunol (2005) 6:902-10. doi:10.1038/ ni1233

24. Proudfoot AE. Chemokine receptors: multifaceted therapeutic targets. Nat Rev Immunol (2002) 2:106-15. doi:10.1038/nri722

25. Johnson Z, Schwarz M, Power CA, Wells TN, Proudfoot AE. Multi-faceted strategies to combat disease by interference with the chemokine system. Trends Immunol (2005) 26:268-74. doi:10.1016/j.it.2005.03.001 
26. Russo RC, Garcia CC, Teixeira MM. Anti-inflammatory drug development: broad or specific chemokine receptor antagonists? Curr Opin Drug Discov Devel (2010) 13:414-27.

27. Pease J, Horuk R. Chemokine receptor antagonists. J Med Chem (2012) 55:9363-92. doi:10.1021/jm300682j

28. Klarenbeek A, Maussang D, Blanchetot C, Saunders M, van der Woning S, Smit M, et al. Targeting chemokines and chemokine receptors with antibodies. Drug Discov Today Technol (2012) 9:e227-314. doi:10.1016/j.ddtec. 2012.09.006

29. Galzi JL, Hachet-Haas M, Bonnet D, Daubeuf F, Lecat S, Hibert M, et al. Neutralizing endogenous chemokines with small molecules. Principles and potential therapeutic applications. Pharmacol Ther (2010) 126:39-55. doi:10.1016/j.pharmthera.2009.12.003

30. Blanchetot C, Verzijl D, Mujic-Delic A, Bosch L, Rem L, Leurs R, et al. Neutralizing nanobodies targeting diverse chemokines effectively inhibit chemokine function. J Biol Chem (2013) 288:25173-82. doi:10.1074/jbc. M113.467969

31. Perry CM. Maraviroc: a review of its use in the management of CCR5-tropic HIV-1 infection. Drugs (2010) 70:1189-213. doi:10.2165/11203940000000000-00000

32. De Clercq E. The AMD3100 story: the path to the discovery of a stem cell mobilizer (Mozobil). Biochem Pharmacol (2009) 77:1655-64. doi:10.1016/j. bcp.2008.12.014

33. Adage T, Piccinini AM, Falsone A, Trinker M, Robinson J, Gesslbauer B, et al. Structure-based design of decoy chemokines as a way to explore the pharmacological potential of glycosaminoglycans. Br J Pharmacol (2012) 167:1195-205. doi:10.1111/j.1476-5381.2012.02089.x

34. RekA,KrennE,KunglAJ. Therapeuticallytargeting protein-glycaninteractions. Br J Pharmacol (2009) 157:686-94. doi:10.1111/j.1476-5381.2009.00226.x

35. Falsone A, Wabitsch V, Geretti E, Potzinger H, Gerlza T, Robinson J, et al. Designing CXCL8-based decoy proteins with strong anti-inflammatory activity in vivo. Biosci Rep (2013) 33:e00068. doi:10.1042/BSR20130069

36. McElvaney OJ, O’Reilly N, White M, Lacey N, Pohl K, Gerlza T, et al. The effect of the decoy molecule PA401 on CXCL8 levels in bronchoalveolar lavage fluid of patients with cystic fibrosis. Mol Immunol (2015) 63:550-8. doi:10.1016/j. molimm.2014.10.013

37. Bedke J, Nelson PJ, Kiss E, Muenchmeier N, Rek A, Behnes CL, et al. A novel CXCL8 protein-based antagonist in acute experimental renal allograft damage. Mol Immunol (2010) 47:1047-57. doi:10.1016/j.molimm. 2009.11.012

38. Adage T, del Bene F, Fiorentini F, Doornbos RP, Zankl C, Bartley MR, et al. PA401, a novel CXCL8-based biologic therapeutic with increased glycosaminoglycan binding, reduces bronchoalveolar lavage neutrophils and systemic inflammatory markers in a murine model of LPS-induced lung inflammation. Cytokine (2015) 76:433-41. doi:10.1016/j.cyto.2015.08.006

39. Piccinini AM, Knebl K, Rek A, Wildner G, Diedrichs-Mohring M, Kungl AJ. Rationally evolving MCP-1/CCL2 into a decoy protein with potent anti-inflammatory activity in vivo. J Biol Chem (2010) 285:8782-92. doi:10.1074/jbc.M109.043299

40. Gschwandtner M, Trinker MU, Hecher B, Adage T, Ali S, Kungl AJ. Glycosaminoglycan silencing by engineered CXCL12 variants. FEBS Lett (2015) 589:2819-24. doi:10.1016/j.febslet.2015.07.052

41. Hoellenriegel J, Zboralski D, Maasch C, Rosin NY, Wierda WG, Keating MJ, et al. The Spiegelmer NOX-A12, a novel CXCL12 inhibitor, interferes with chronic lymphocytic leukemia cell motility and causes chemosensitization. Blood (2014) 123:1032-9. doi:10.1182/blood-2013-03-493924

42. Vanheule V, Janssens R, Boff D, Kitic N, Berghmans N, Ronsse I, et al. The positively charged $\mathrm{COOH}$-terminal glycosaminoglycan-binding CXCL9 (74-103) peptide inhibits CXCL8-induced neutrophil extravasation and monosodium urate crystal-induced gout in mice. J Biol Chem (2015) 290:21292-304. doi:10.1074/jbc.M115.649855

43. Vanheule V, Vervaeke P, Mortier A, Noppen S, Gouwy M, Snoeck R, et al. Basic chemokine-derived glycosaminoglycan binding peptides exert antiviral properties against dengue virus serotype 2, herpes simplex virus- 1 and respiratory syncytial virus. Biochem Pharmacol (2016) 100:73-85. doi:10.1016/j. bcp.2015.11.001

44. Van Raemdonck K, Berghmans N, Vanheule V, Bugatti A, Proost P, Opdenakker G, et al. Angiostatic, tumor inflammatory and anti-tumor effects of CXCL4(47-70) and CXCL4L1(47-70) in an EGF-dependent breast cancer model. Oncotarget (2014) 5:10916-33. doi:10.18632/oncotarget.2538

45. Loos T, Mortier A, Proost P. Chapter 1. Isolation, identification, and production of posttranslationally modified chemokines. Methods Enzymol (2009) 461:3-29. doi:10.1016/S0076-6879(09)05401-9

46. Gerlza T, Hecher B, Jeremic D, Fuchs T, Gschwandtner M, Falsone A, et al. A combinatorial approach to biophysically characterise chemokine-glycan binding affinities for drug development. Molecules (2014) 19:10618-34. doi:10.3390/molecules190710618

47. Robinson DE, Buttle DJ, Short RD, McArthur SL, Steele DA, Whittle JD. Glycosaminoglycan (GAG) binding surfaces for characterizing GAGprotein interactions. Biomaterials (2012) 33:1007-16. doi:10.1016/j. biomaterials.2011.10.042

48. Proost P, Loos T, Mortier A, Schutyser E, Gouwy M, Noppen S, et al. Citrullination of CXCL8 by peptidylarginine deiminase alters receptor usage, prevents proteolysis, and dampens tissue inflammation. J Exp Med (2008) 205:2085-97. doi:10.1084/jem.20080305

49. Amaral FA, Costa VV, Tavares LD, Sachs D, Coelho FM, Fagundes CT, et al. NLRP3 inflammasome-mediated neutrophil recruitment and hypernociception depend on leukotriene $\mathrm{B}(4)$ in a murine model of gout. Arthritis Rheum (2012) 64:474-84. doi:10.1002/art.33355

50. Phillipson M, Heit B, Colarusso P, Liu L, Ballantyne CM, Kubes P. Intraluminal crawling of neutrophils to emigration sites: a molecularly distinct process from adhesion in the recruitment cascade. J Exp Med (2006) 203:2569-75.

51. Vandercappellen J, Liekens S, Bronckaers A, Noppen S, Ronsse I, Dillen C, et al. The $\mathrm{COOH}$-terminal peptide of platelet factor- 4 variant (CXCL4L1/ PF-4var47-70) strongly inhibits angiogenesis and suppresses B16 melanoma growth in vivo. Mol Cancer Res (2010) 8:322-34. doi:10.1158/1541-7786. MCR-09-0176

52. Ihrcke NS, Wrenshall LE, Lindman BJ, Platt JL. Role of heparan sulfate in immune system-blood vessel interactions. Immunol Today (1993) 14:500-5. doi:10.1016/0167-5699(93)90265-M

53. Zhang G, Ezura Y, Chervoneva I, Robinson PS, Beason DP, Carine ET, et al. Decorin regulates assembly of collagen fibrils and acquisition of biomechanical properties during tendon development. J Cell Biochem (2006) 98:1436-49. doi:10.1002/jcb.20776

54. Bishnoi M, Jain A, Hurkat P, Jain SK. Chondroitin sulphate: a focus on osteoarthritis. Glycoconj J (2016) 33(5):693-705. doi:10.1007/s10719-016-9665-3

55. Petri B, Phillipson M, Kubes P. The physiology of leukocyte recruitment: an in vivo perspective. JImmunol (2008) 180:6439-46. doi:10.4049/ jimmunol.180.10.6439

56. Phillipson M, Kubes P. The neutrophil in vascular inflammation. Nat Med (2011) 17:1381-90. doi:10.1038/nm.2514

57. Lortat-Jacob H. The molecular basis and functional implications of chemokine interactions with heparan sulphate. Curr Opin Struct Biol (2009) 19:543-8. doi:10.1016/j.sbi.2009.09.003

58. Rot A. Chemokine patterning by glycosaminoglycans and interceptors. Front Biosci (Landmark Ed) (2010) 15:645-60. doi:10.2741/3638

59. Gandhi NS, Mancera RL. The structure of glycosaminoglycans and their interactions with proteins. Chem Biol Drug Des (2008) 72:455-82. doi:10.1111/j.1747-0285.2008.00741.x

60. Shi X, Zaia J. Organ-specific heparan sulfate structural phenotypes. J Biol Chem (2009) 284:11806-14. doi:10.1074/jbc.M809637200

61. Barmore AJ, Castex SM, Gouletas BA, Griffith AJ, Metz SW, Muelder NG, et al. Transferring the C-terminus of the chemokine CCL21 to CCL19 confers enhanced heparin binding. Biochem Biophys Res Commun (2016) 477:602-6. doi:10.1016/j.bbrc.2016.06.098

62. Verkaar F, van Offenbeek J, van der Lee MM, van Lith LH, Watts AO, Rops AL, et al. Chemokine cooperativity is caused by competitive glycosaminoglycan binding. J Immunol (2014) 192:3908-14. doi:10.4049/jimmunol.1302159

63. Hjorto GM, Larsen O, Steen A, Daugvilaite V, Berg C, Fares S, et al. Differential CCR7 targeting in dendritic cells by three naturally occurring CC-chemokines. Front Immunol (2016) 7:568. doi:10.3389/fimmu.2016.00568

64. Schumann K, Lammermann T, Bruckner M, Legler DF, Polleux J, Spatz JP, et al. Immobilized chemokine fields and soluble chemokine gradients cooperatively shape migration patterns of dendritic cells. Immunity (2010) 32:703-13. doi:10.1016/j.immuni.2010.04.017 
65. Connell BJ, Sadir R, Baleux F, Laguri C, Kleman JP, Luo L, et al. Heparan sulfate differentially controls CXCL12alpha- and CXCL12gamma-mediated cell migration through differential presentation to their receptor CXCR4. Sci Signal (2016) 9:ra107. doi:10.1126/scisignal.aaf1839

66. Schall TJ, Proudfoot AE. Overcoming hurdles in developing successful drugs targeting chemokine receptors. Nat Rev Immunol (2011) 11:355-63. doi: $10.1038 /$ nri2972

67. Hileman RE, Fromm JR, Weiler JM, Linhardt RJ. Glycosaminoglycan-protein interactions: definition of consensus sites in glycosaminoglycan binding proteins. Bioessays (1998) 20:156-67. doi:10.1002/(SICI)1521-1878(199802) 20:2<156::AID-BIES8>3.3.CO;2-\#

68. Tanino Y, Coombe DR, Gill SE, Kett WC, Kajikawa O, Proudfoot AE, et al. Kinetics of chemokine-glycosaminoglycan interactions control neutrophil migration into the airspaces of the lungs. J Immunol (2010) 184:2677-85. doi:10.4049/jimmunol.0903274

69. Martel-Pelletier J, Boileau C, Pelletier JP, Roughley PJ. Cartilage in normal and osteoarthritis conditions. Best Pract Res Clin Rheumatol (2008) 22:351-84. doi:10.1016/j.berh.2008.02.001

70. Jerosch J. Effects of glucosamine and chondroitin sulfate on cartilage metabolism in OA: outlook on other nutrient partners especially omega-3 fatty acids. Int J Rheumatol (2011) 2011:969012. doi:10.1155/2011/969012
71. Dyer DP, Salanga CL, Volkman BF, Kawamura T, Handel TM. The dependence of chemokine-glycosaminoglycan interactions on chemokine oligomerization. Glycobiology (2016) 26:312-26. doi:10.1093/glycob/ cwv100

72. Hamel DJ, Sielaff I, Proudfoot AE, Handel TM. Chapter 4. Interactions of chemokines with glycosaminoglycans. Methods Enzymol (2009) 461:71-102. doi:10.1016/S0076-6879(09)05404-4

Conflict of Interest Statement: The authors declare that the research was conducted in the absence of any commercial or financial relationships that could be construed as a potential conflict of interest.

Copyright (c) 2017 Vanheule, Boff, Mortier, Janssens, Petri, Kolaczkowska, Kubes, Berghmans, Struyf, Kungl, Teixeira, Amaral and Proost. This is an open-access article distributed under the terms of the Creative Commons Attribution License (CC BY). The use, distribution or reproduction in other forums is permitted, provided the original author(s) or licensor are credited and that the original publication in this journal is cited, in accordance with accepted academic practice. No use, distribution or reproduction is permitted which does not comply with these terms. 